\title{
Between Beats: Linking Player Engagement to Advertisement Frequency and Intrusiveness
}

\author{
Markus Hirsimäki \\ Quicksave Interactive \\ Helsinki, Finland \\ hirsimaki.markus@gmail.com
}

\author{
Paula Alavesa, Leena Arhippainen \\ Information Technology and Electrical Engineering, University of Oulu \\ Oulu, Finland \\ paula.alavesa, leena.arhippainen@oulu.fi
}

\begin{abstract}
Mobile phones are a popular platform for gaming in addition to being the most ubiquitous one. Monetization of free to play games with embedded and interstitial advertisements is one of the main sources of income for mobile game creators. We used a constructive approach in this study. A mobile game developed during the study, Between Beats, was used to survey the influence of interstitial advertisement on selected aspects of player experience. The study was conducted by deploying the game to Google Play and guiding the players, after gameplay, to an online survey. The survey was answered by 51 participants who were divided randomly into four groups based on how much they were subjected to interstitial or rewarded advertisements while playing. Our results show that embedding rewarded advertisements to a situation where there already is interstitial advertisements, resulted in reduction of perceived advertisement intrusiveness and increase in advertisements viewed. Player engagement remained constant in all groups. Our findings complement earlier findings on the use of rewarded advertisements in mobile games.
\end{abstract}

\section{INTRODUCTION}

Advertisement is one of the main ways of monetizing mobile games. While gamers may have gotten used to different forms of embedded advertisement, they still influence player experience and many mobile game creators need to balance between optimal player experience and finding income [1], [2]. There is existing literature already on aspects closely related to our research and due to the relevance of advertisement intrusiveness to the industry, there are also many industry case studies focusing on advertisement. What these studies show is that the way advertisements are framed correlates with how advertisements are perceived and interacted with, which ultimately influences the profits [1]-[3]. While the topic is widely studied the gaming devices, games and advertisements evolve, which means the topic requires revisiting to keep the practices up to date.

In this study we revisit the topic of advertisement intrusiveness and its relationship to player experience by using constructive method [4]. A mobile game, Between Beats [5], was designed, developed and used as a construct to study selected aspects of player experience.

The broad research questions for this study were:

- How an increase in advertising influences player experience in mobile games?

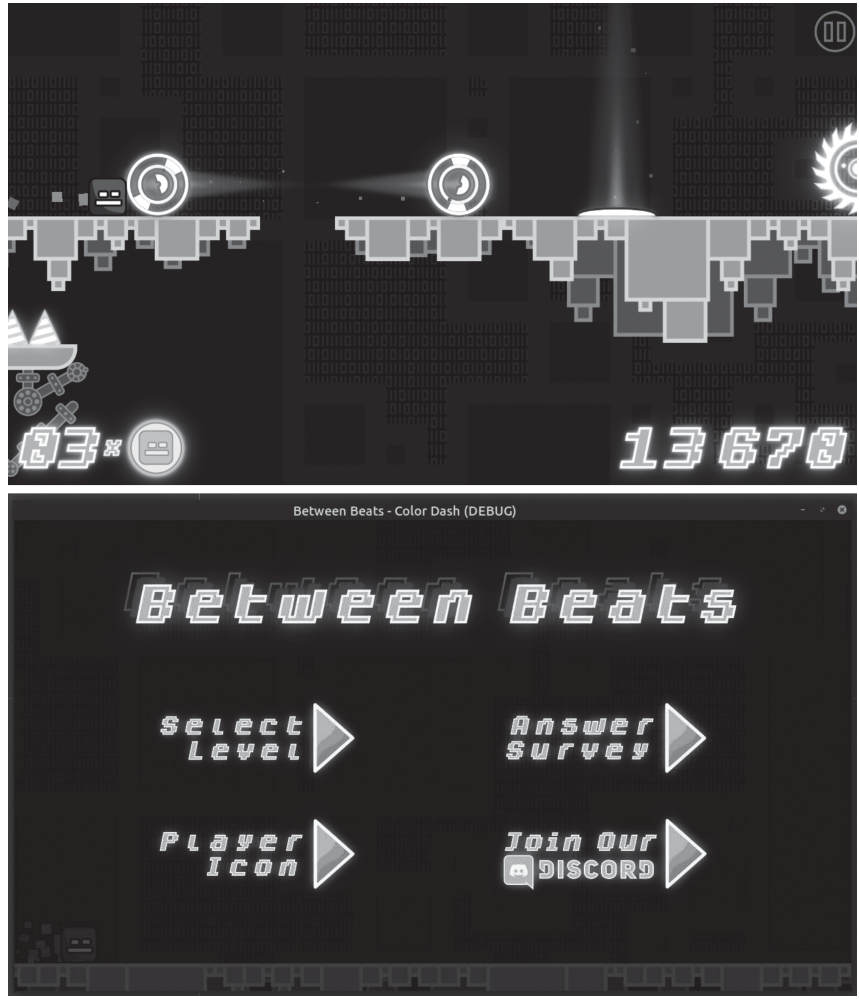

Fig. 1. A screenshot of Between Beats (top), the game construct used for this study, during gameplay and the menu screen (bottom) with the option for participating to the survey.

- How can an increase in advertising be framed in such a way that it has a minimal negative impact on player experience in context of mobile games?

Of these questions the first is more specific and directly targeted in this study and the latter scopes the more explorative target for the current and future studies. In this paper we report a constructive process used in this study and results from gameplay and online survey with 51 participants.

\section{RELATED WORK}

Burns et al. [2] found in their study looking into player retention and advertisement that there is a weak link between player retention and advertisement density, whereas the con- 
tent of the game itself had a stronger link to player retention. Their findings are not indisputable, some still suggest that increasing advertising will reduce player retention due to the perceived annoyance [3]. The study by Burns et al. [2], despite having limitations, agrees with the other studies [2]; the way advertisements are framed has a correlation with how advertisements are perceived and interacted with, which ultimately influences the monetization.

Kim and Lee [1] used two mobile games to study the connections between reward-based and permission-based advertisements with successful and failed gameplay outcomes. Additionally, they studied connections between reward-based, permission-based and interstitial advertisements in relation to dramatized, real, and mixed game scenes used in advertisements. According to their findings both rewarded and permission-based advertisements yielded better attitudes and download intents than interstitial advertisements. Additionally, there was no significant difference between reward-based advertisements and permission-based advertisements. [1]

Both of the aforementioned studies points towards the same direction; the way the advertisements are framed has an effect on their effectiveness [1], [2]. The framing can occur both in the form of asking for the player consent as well as situating the advertisements to the gameplay experience.

Rewarded video advertisements has become a popular form for advertisements on the mobile games market [6]-[9]. Khai Chiong et al. [6], had a data set of nearly one million mobile advertising impressions to study rewarded video advertisement. The study focused different hypothesis around the length of the advertisement, its associated reward, and the temptation effect. The findings were that "...incentivized advertising leads to lower users' click-through rates, but a higher overall install rate of the advertised app" [6]. They also found that switching to incentivized advertising increases the publisher's revenue. [6]

Similar results on rewarded advertising have also been published directly by advertising networks. Two such examples are two different infographics published by AdColony [7] and MoPub [8]. A case study by MoPub chose a successful strategy to begin with a negative return over investment, and switching to rewarded advertising as opposed to the initial interstitial advertising used. [7] AdColony [8], had a month lasting study with 60000 unique players of a mobile game that initially was already offering rewarded advertising. They added a different type of reward, where the player character could respawn, in other words start their current level with all their in-game bonuses and collectibles, if the player chooses to watch an advertisement. This drove a $232 \%$ increase in average revenue per daily active user. The change also caused a stable increase of $104 \%$ in session count and an increase in session lengths [8]. In this study we designed and developed a game construct to study how embedded advertisements influence player experience. The study process is depicted in the Fig. 2 and will be introduced more thoroughly in the following chapters.

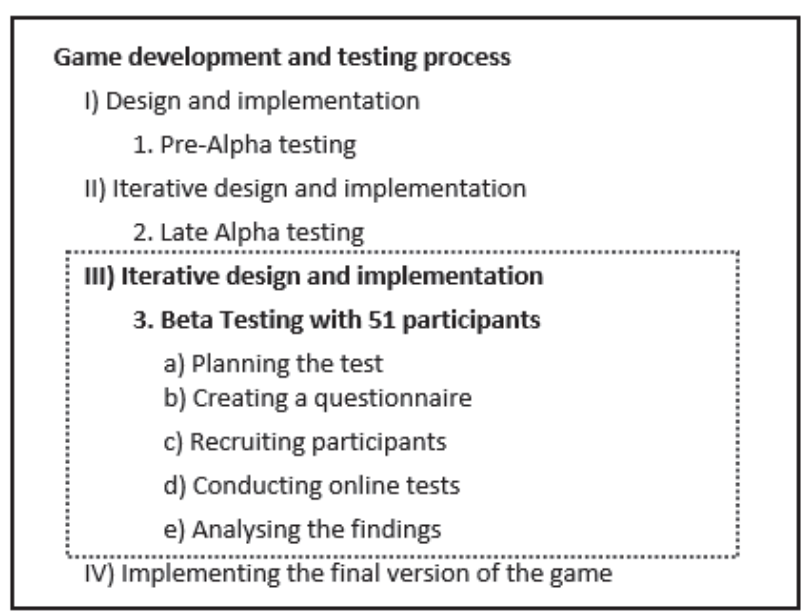

Fig. 2. Process of the study presented in this paper

\section{GAME DEVELOPMENT}

Design and implementation are relevant aspects in constructive research process, we therefore in this chapter describe the design and technical implementation of the game construct Between Beats.

\section{A. Design process}

The Between Beats design process followed so called conceptual blending [10]-[12] of the following influences through iterative process.

The colour switch is a genre solely based on a success of an original game Color Switch, which released for mobile platforms 2015 [13] and was a success with over 200 million downloads [13]-[15]. This success resulted into many games mimicking the visual style, name, and game mechanics, creating a mobile game genre of its own. Just like in the original Color Switch and its many clones, in Between Beats the game environment has different sections which can only be passed if the player character has a matching color. Usually in these games the player will not change the character's color, but rather controls its movement and the elements in the game environment change the character's color. Battle royale style of games spans a wide variety styles, platforms and game mechanics, where the goal is to be the last player standing either against the hostility of the environment or other players. In Between Beats the player avoids hazards and obstacles in the game. The game challenge is created by procedurally generated infinite levels which create increasingly difficult last-man-standing competition between the player and the game.

The process of conceptual blending was such that the initial idea, and the core mechanic, was to use the "colour switch" style of controlling the game solely by switching a color of the player object, opposed to more traditional movement tactics. The other mechanics and influences were then iteratively grafted onto this core. Conceptual blending was introduced by 
Mark Turner and Gilles Fauconnier [10]. The theory initially focused on linguistics and cognition [10]-[12]. It can be described pragmatically as new meaning that arises from the combination of two or more design ideas [16]. Later Raymond W. Gibbs Jr. [17] has combined the original theory and practice into a framework. Conceptual blending, has been successfully applied to game development, games such as the Color Switch [15] or the Crypt of the Necrodancer [18] both combine two unrelated mechanics resulting in a novel game.

\section{B. Technical implementation}

Between beats (Fig. 1) has been implemented on an open source Godot Engine [19]. As elaborated earlier, the game has been inspired by four mobile game genres: the endless runner, the music games genre, the color switch genre and the battle royale games. The game features a seemingly endless track on which the player progresses. The game also contains a system that creates procedurally playable content from a seed value using a random number generator. This has been done to reduce the amount of manual labor spent on creating playable levels and to provide replay value for the players. The game music influence shows in that Between Beats matches the music tempo to gameplay with a so called beatmap, a map consisting of game elements (Fig. 3).

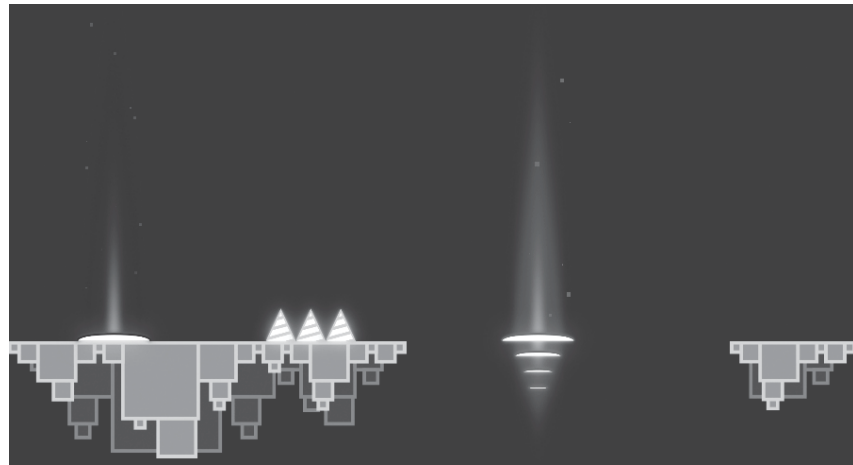

Fig. 3. Screenshot featuring an example beatmap outside of the game in late Alpha phase of development. The top and bottom edges of the image are cropped, the left and right edges are at the boundaries of the beatmap.

The available individual elements (Fig. 4) to be placed on the game map were numerous.

These beatmaps denote the hand crafted sections of infinite levels that can be put together based on various rules to procedurally generate more level as the player moves through it (Fig. 5). The vast majority of all animations seen in the game are created procedurally.

Background music plays an important role in the game. When the player's inputs match the beats per minute of the background music, the game character will switch its color in the correct rhythm to pass all interactables. When these two become mismatched, it will generally result in the character's death. Audacity [20], a free and open source audio editor was was used to record, edit, mix, and master all the audio used in the game.

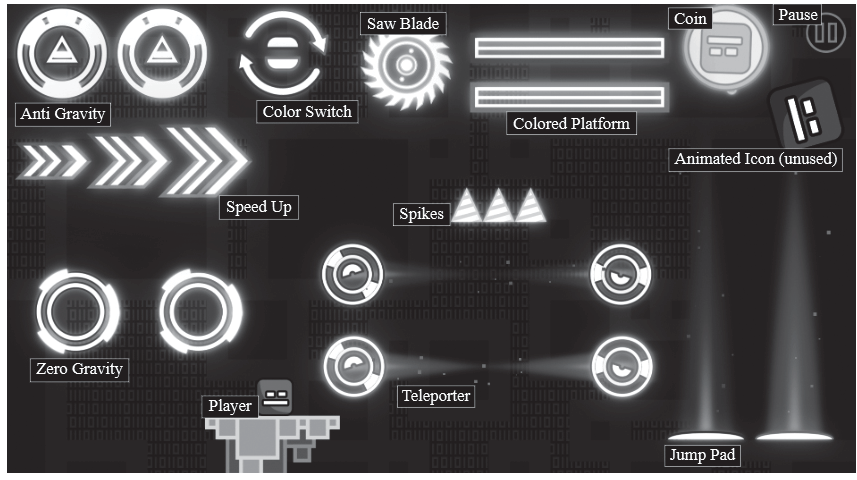

Fig. 4. The used game elements

The generator algorithm used for procedural content creation initializes itself by placing down the first hardcoded beatmap, which requires no input from the player, but allows the player to orient themselves. After this step, the algorithm updates its state based on the metadata flags of the latest beatmap. The following information is updated based on metadata such as the accumulating horizontal coordinate for placing next beatmap, the accumulating delta-height, and lastly, the generator's gravity state.

The advertising, banner advertisement and interstitial advertising, required for this study was implemented using a Godot engine plugin, godot-applovin-max, by GitHub user DrMoriarty [21]. The plugin allows the game to fetch and display advertising provided by the AppLovin MAX mediator framework [22]. Implementing the advertising had more steps that one would have expected. Different plugins were tried for implementation, and a console overlay was implemented to aid in debugging. Both private individuals and corporate entities had to be contacted for support, and testing needed to be conducted with participants recruited from Discord to troubleshoot bugs. This was however necessary for this study to enable some control over the advertisement contents viewed by the study participants.

\section{Gameplay}

Between Beats gameplay Fig. 1 uses a simple control scheme common in many mobile games. The only input type is touch. During the gameplay the player navigates a track where the player moves automatically from left to right. The only influence the player has is changing the colour of the player character by tapping the screen.The gameplay is synchronized with the game music so that the control input needs to match the tempo of the music, its beats per minute. How player passes obstacles is influences by the player character's colour. When the character is blue one can interact with blue objects and when the character is red it can interact with red objects. In addition, there are hazards, traps and coins on the game track. A video of the gameplay can be found at [23]. 


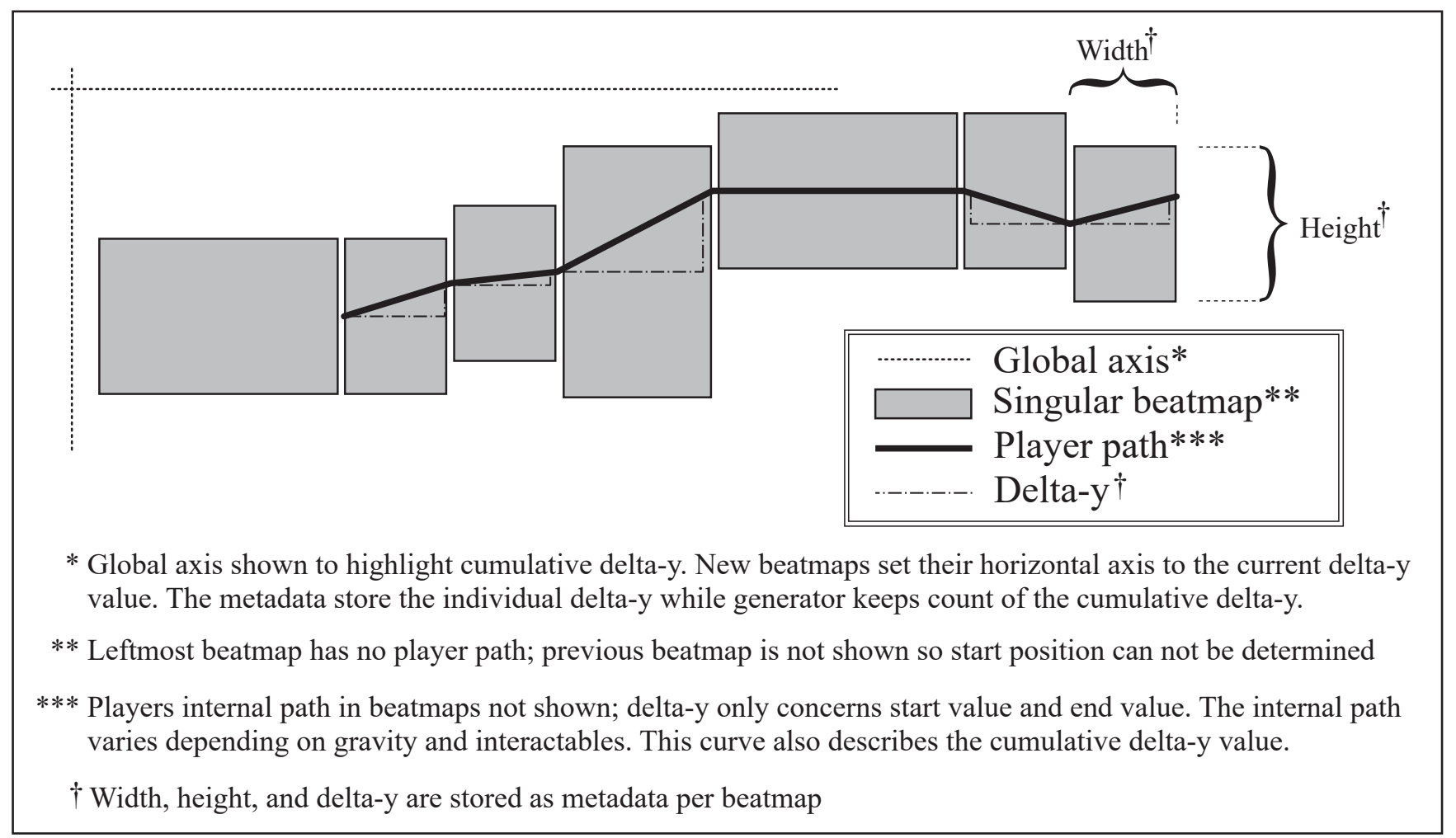

Fig. 5. A graphical abstraction of the level generator implementation. Each one of the grey boxes is a unique beatmap, such as the one seen in figure 3. Each beatmap is placed in such a way that the player's path always starts in the middle.

\section{Evaluation Method}

Constructive method [4] was used. Between Beats, the construct, was deployed to Google Play and test users were recruited via Discord and university of Oulu Finland mailing lists in Spring 2021. The social distancing guidelines due to the COVID-19 pandemic would have prevented a controlled study setup for evaluation, which is why the evaluation was planned to be conducted in this manner from the beginning. The players were instructed on how to download and install the Between Beats game from Google Play and after gameplay they were guided Fig. 1, to an online survey. The survey contained a request for informed consent, demographic questions and statements from the consumer video game engagement scale [24] measuring cognitive, affective, and behavioral engagement. These three categories contain a total of 29 statements such as "Anything related to this video-game grabs my attention" [24], [25]. 1-5 Likert scale was used for the statements.

\section{A. Participants}

The survey was answered by 51 participants who were divided into four groups based on how much they were subjected to interstitial or rewarded advertisements while playing. The players were also divided into three groups based on the recent mobile gaming experience in hours per week which used the following categorization: "15 or less", "16-30", and
"31 or more". The original categorization by Hussain and Griffiths [26] divides gamers based on the hours played into three groups casual, regular and excessive gamers. 39 of the participants $(76,5 \%)$ played mobile games $15 \mathrm{~h}$ or less a week and was thus were regarded as casual players. Seven $(13,7 \%)$ of the participants were regular and five $(9,8 \%)$ excessive gamers based on their own observation of the recent mobile gaming experience. 13 of the participants had tested the earlier version of the game and the rest (38) had no prior experience of the game.

38 of the participants were male, 12 female and one did not enclose their gender. Based on the age groups: aged 13(7), 14-17(14), 18-23(16), 24-29(10), 30-39(3) and 40-49(1), they were mostly young adults (Fig. 6). 41 of the participants $(80,4 \%)$ were from EU and Russia, only ten participants were outside these areas.

The participants were not allowed to access the survey questionnaire if they had not played the game for at-least 15 minutes or played through the level 1.30 of the participants $(58,8 \%)$ played the game $16-30$ minutes before answering the survey. $18(35,3 \%)$ played 15 minutes or less and two played $31-45$ minutes. Only one reported playing the game 61 minutes or more.

\section{B. The Four Test Groups}

The participants were divided into four groups G1-4. G4 received no interstitial or rewarded advertisements. Each group 


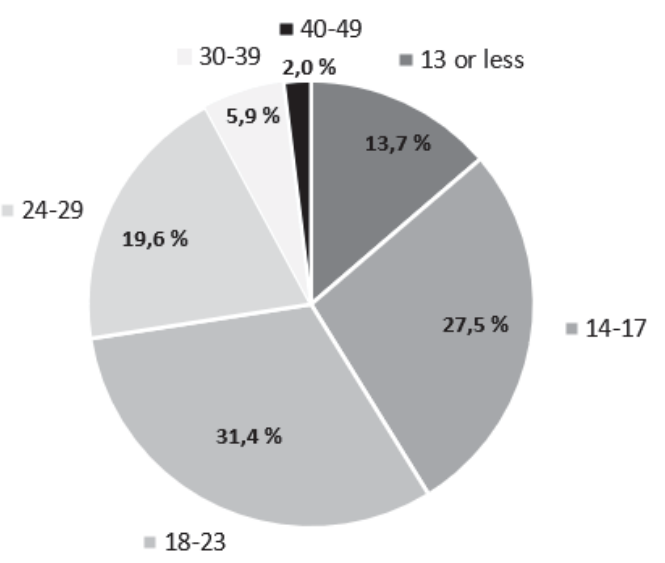

Fig. 6. Percentage of the participants in each age group

had though banner advertising, since it was not removable. In contrast G3 received both interstitial and rewarded advertisements. G2 received only rewarded advertisements and G1 received only interstitial advertisements. The amount of banner advertisement was not controllable, opposite to rewarded and interstitial advertisements that were available upon request.

The Discord members are over-represented in G4 and under-represented in the other groups (Table I). Players that had no previous experience are under-represented in G1 and over-represented in the rest of the groups. Previous experience with the game had no influence on the answers, but there were differences in the how Discord members and university mailing list recruits related to the advertisements.

TABLE I. TEST GROUP NAMES, SIZE, AND THE MEAN NUMBER OF FULLSCREEN ADVERTISEMENTS WATCHED BY EACH MEMBER OF THE GROUP

\begin{tabular}{|c|c|c|}
\hline & $\begin{array}{c}\text { Rewarded } \\
\text { advertising }\end{array}$ & $\begin{array}{c}\text { No rewarded } \\
\text { advertising }\end{array}$ \\
\hline $\begin{array}{c}\text { Interstitial } \\
\text { advertising }\end{array}$ & $\mathrm{n}=9(17.6 \%), 7.06$ & $\mathrm{n}=11(21.6 \%), 2.14$ \\
\hline $\begin{array}{c}\text { No interstitial } \\
\text { advertising }\end{array}$ & $\mathrm{n}=12(23.5 \%), 0.58$ & $\mathrm{n}=19(37.3 \%), 0.63$ \\
\hline
\end{tabular}

\section{RESULTS}

\section{A. Advertisement Intrusiveness}

The intrusiveness of advertising was measured using four statements. These statements were as follows; "The in-game advertisements were distracting.", "The in-game advertisements were too frequent.", "The in-game advertisements were not too long.", and "The in-game advertisements were interesting." During analysis, the last two of these had their scale inverted (Table II). One-way between groups ANOVA test was done to both intrusiveness and engagement statements from the questionnaire.
TABLE II. ADVERTISEMENT INTRUSIVENESS BASED ON FOUR STATEMENTS

\begin{tabular}{|c|c|c|c|c|c|}
\hline Group & Users & $\begin{array}{c}\text { Sample } \\
\text { count }\end{array}$ & $\begin{array}{c}\text { Samples } \\
\text { mean }\end{array}$ & $\begin{array}{c}\text { Samples } \\
\text { SD }\end{array}$ & p-value \\
\hline G1 & 11 & 44 & 4.20 & $0.90 \pm 0.14$ & \multirow[t]{4}{*}{$<0.001$} \\
\hline G2 & 12 & 48 & 2.73 & $1.28 \pm 0.19$ & \\
\hline G3 & 9 & 36 & 3.722 & $1.14 \pm 0.19$ & \\
\hline G4 & 19 & 76 & 3.05 & $1.19 \pm 0.14$ & \\
\hline
\end{tabular}

Player engagement was measured using a survey based on the consumer videogame engagement scale (CVES) by Abbasi et al. [27], [28]. In the original data set there were significant differences between the participants recruited from university mailing lists and Discord. Normalization was done by scaling the answers down from the Discord group. A constant was used to multiply each answer in one category if the answer was given by a Discord member. This constant was chosen so that within the category both the Discord group and the university mailing list group had the same average value. Without this sample sizes would have become too small; smallest subset would have been only three samples as opposed to nine. Significant differences were found in one category of engagement: Affective engagement (Table III).

TABLE III. STATISTICALLY SIGNIFICANT RESULTS ON PLAYERS' AFFECTIVE ENGAGEMENT

\begin{tabular}{|c|c|c|c|c|c|}
\hline Group & Users & $\begin{array}{c}\text { Sample } \\
\text { count }\end{array}$ & $\begin{array}{c}\text { Samples } \\
\text { mean }\end{array}$ & $\begin{array}{c}\text { Samples } \\
\text { SD }\end{array}$ & \multirow{2}{*}{ p-value } \\
\hline G1 & 11 & 110 & 1.95 & $0.84 \pm 0.080$ & \multirow{2}{*}{0.045} \\
G2 & 12 & 120 & 2.05 & $0.86 \pm 0.078$ & \\
G3 & 9 & 90 & 1.71 & $0.75 \pm 0.079$ & \multirow{2}{*}{} \\
\cline { 1 - 4 } G4 & 19 & 190 & 1.91 & $0.95 \pm 0.069$ & \\
\hline
\end{tabular}

\section{B. Outlier observations}

Most of the player experience questionnaire items on engagement gave us inconclusive results with p-values outside the confidence interval. An interesting finding was the differences in affective and behavioural engagement between the two groups participants recruited via Discord and University mailing lists. The affective and behavioral engagement are higher in the group recruited from Discord (Table IV). In open questionnaire items it appear that the university students participating in this research were more resentful on having to watch commercials while participating in a research. This poses an interesting limitation for academic research conducted on advertisements and mobile games with sample recruited mainly from university students. 
TABLE IV. THE DIFFERENCES IN ENGAGEMENT BETWEEN PLAYERS RECRUITED FROM DIFFERENT VENUES

\begin{tabular}{|c|c|c|c|c|c|}
\hline \multicolumn{7}{|c|}{ Affective engagement (10 questions) } \\
\cline { 1 - 5 } Group & Users & $\begin{array}{c}\text { Sample } \\
\text { count }\end{array}$ & $\begin{array}{c}\text { Samples } \\
\text { mean }\end{array}$ & $\begin{array}{c}\text { Samples } \\
\text { SD }\end{array}$ & p-value \\
\hline Discord & 29 & 290 & 3.01 & $\begin{array}{c}1.11 \pm \\
0.065\end{array}$ & $<0.001$ \\
\cline { 1 - 5 } Email & 22 & 220 & 1.91 & $\begin{array}{c}1.07 \pm \\
0.072\end{array}$ & \\
\hline \multicolumn{7}{|c|}{ Behavioral engagement (8 questions) } \\
\hline Group & Users & $\begin{array}{c}\text { Sample } \\
\text { count }\end{array}$ & $\begin{array}{c}\text { Samples } \\
\text { mean }\end{array}$ & $\begin{array}{c}\text { Samples } \\
\text { SD }\end{array}$ & p-value \\
\hline Discord & 29 & 232 & 2.84 & $\begin{array}{c}1.21 \pm \\
0.079\end{array}$ & \multirow{2}{*}{$<0.001$} \\
\cline { 1 - 4 } Email & 22 & 176 & 1.82 & $\begin{array}{c}1.08 \pm \\
0.081\end{array}$ & \\
\hline
\end{tabular}

\section{Player experiences}

In the survey we also collected qualitative feedback for game design purposes. The questions were divided for negative and positive experience to encourage responses on both aspects of gameplay. When we asked on open question "Was there anything positive about the game that you remember in particular?" 31 participants gave examples of the aspects they liked. For the question "Was there anything negative about the game that you remember in particular? 25 players mentioned aspects they did not like.

Most of the usability problems were minor. Some, especially those recruited from university mailing lists, clearly did not like the advertisements. The players also reported emergent problems; sometimes banner advertisements would cover interactables during the gameplay, which would leave the player with minimal a amount of reaction time. Several players also noted disliking how long some interstitial advertisements were. Interestingly, these notes did not apply to rewarded advertising despite the musing the same source for loading adverts. A different type of advertisement related problem reported by one player was general confusion as to why would a Beta version of the game even contain advertisements like one young participant commented: "It seems abnormal to include ads in a beta of a game" (ID7, Male, 14-17y). This comment reinforces the assumption that despite active discussion the Discord community, as intended, were not aware of the focus of the study. There may also be some cultural differences relating to attitudes towards advertisements, for instance, this person was from North America. This is a topic that, however, needs further research. According to statements (Fig. 7) the ingame advertisements were not perceived very positively, for instance, 22 players perceived them as distracting. Majority (37) of the participants did not perceive the ingame advertisements interesting. However, studying the contents of the advertisement is outside the scope of this research.

The majority of the feedback was positive and in relation to three aspects: the graphics, the animations, and the background music (Fig. 8). One positive comment included praise on the level design and how the games difficulty increased through levels. Similarly the graphic design gained positive remarks although one player reported disliking the graphical

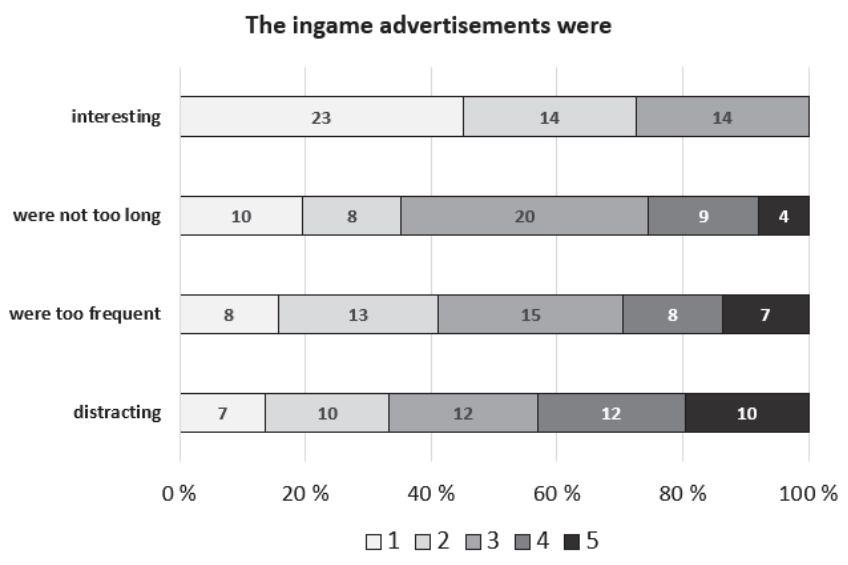

Fig. 7. Players' perceptions of the ingame advertisements

style of the game. A minority of the players disliked the difficulty progression of the game, while some noted that despite disliking it they thought it was an integral part of the experience. Several players noted that they were happy to see two variations of the player icon already unlocked at the very beginning of the game. Some players also described the gameplay as being smooth, which was one of the very early design goals. The ability to unlock new icons (Fig. 9) and seemingly gain progression that way was also described as being a positive experience with many players hoping for more levels and icons. Within the Discord community, some players started competing amongst themselves on who could achieve the highest score; while the score meter did not gain any specific notes from the players it served an important purpose as it allowed for this sort of competition amongst the players.

A) I liked the ingame background music. B) The ingame sound effects were distracting.

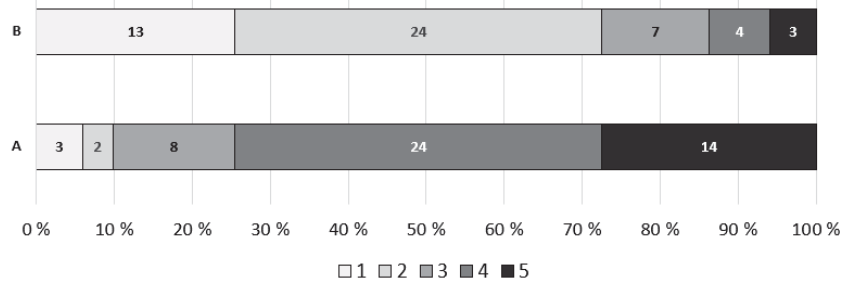

Fig. 8. Players' perceptions of the game audio

\section{Relationship to other games}

The survey contained two open ended questions intended to gauge how the players associated the game with other titles they were familiar with. The majority (37) of the respondents mentioned a similarity to Geometry Dash with some answers containing names of multiple other games. Some players noted that the most important similarity to Geometry Dash was the 


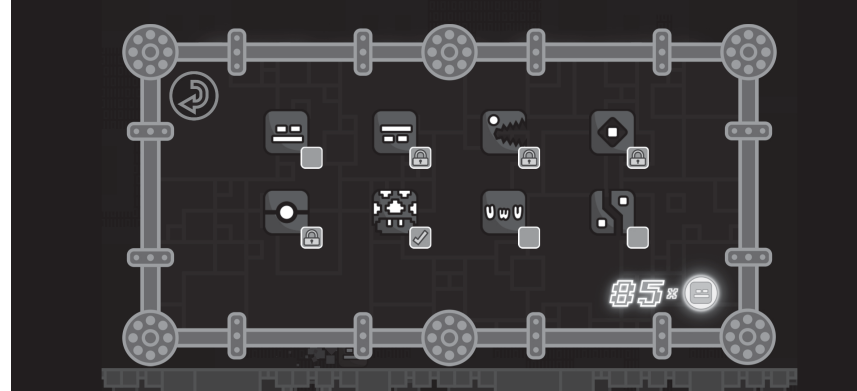

Fig. 9. Players can unlock new icons when they have earned enough coins

visual style and specifically how the character looked like. In the order of how often the games were mentioned, the most frequent titles were Chameleon Run, Super Meat Boy, and classic Sonic the Hedgehog games. Many titles were also mentioned only once such as The Impossible Game, OSU, Yoo Ninja, Gravity Guy, Hue and Spin Rhythm. In addition to naming specific titles the players were also asked to name genres. This proved to provide significantly less answers; only five categories were mentioned: rhythm game, arcade game, puzzle game, platformer, and color switching game.

\section{E. Player feedback}

The tests provided a variety of feedback relating to general improvements. Some of the suggestions were already under consideration, while some were novel. An example of something that had been considered was a request for music volume control as some players considered the audio to be either too loud or quiet. A similar suggestion was request for adding a confirmation message when closing the game from the main menu. Many suggestions were previously unconsidered; some players suggested "easter eggs" while others' suggestions focused on overall quality of the gameplay such as going to the next level without visiting main menu after one level was completed. The level-end screen was subject to multiple suggestions such as adding the ability to drag and drop the animated coins that flood the screen and displaying coins gained from watching rewarded advertisements separately.

\section{DISCUSSION}

Our results agree with related literature on that the number of advertisements viewed does not seem to strictly correlate with the amount of perceived intrusion; G3 has a vastly higher number of advertisements viewed than any other group while still having lower perceived intrusion than G1. The difference between G3 and G1 is that while both groups saw interstitial advertisements only G3 had rewarded advertisements. We found that perceived intrusiveness of advertising was lowered if rewarded advertising was added to a situation already containing interstitial advertising. Furthermore, adding rewarded advertising with no interstitial advertising lowered perceived intrusiveness when we already had banner advertising. G2 (Table I), which saw rewarded advertisements without interstitial advertisements had the lowest perceived advertisement intrusiveness. The perceived intrusion for G2 was lower than for G4, which saw no rewarded and no interstitial advertisements. It is important to note that each group had banner advertising.

\section{A. Limitations and future work}

Our sample was small (51) for an online survey where participants were divided between four conditions. In the future, we would like to extend this survey for a bigger sample to be able to get more conclusive and novel results.

We noticed that where the participants had been recruited influenced the results. Participants recruited via University mailing list and Discord differed on how they perceived the advertisements. In the open questions of the questionnaire one of the participants recruited via University mailing lists stated they did like having to watch advertisements in a game that was used for research. Perceived advertisement intrusiveness was not strongly effected by the players having previous experience with the game; group with previous experience and group with no previous experience had negligibly small difference between the mean values of the groups, 0.2. This was accompanied by a high p-value of 0.320 . These findings suggest that we cannot show the advertisement intrusiveness being biased in terms of previous experience with the game. The results, however, are very different between the subjects recruited from the general public and university mailing lists, on player engagement. The player engagement survey presents three engagement categories; cognitive, affective, and behavioral engagement. There was a clear difference between players that originated from Discord and players that originated from email lists. To keep the normalization process simple and avoid over-correcting, answers were lowered in a linear manner. Other options were considered; e.g. correction could have been done by lowering averages of Discord group while increasing them for the university email list group. While this approach is not perfect, we assume that it will lower the overall bias. In the future studies we will aim at recruiting more participants from the general public, with focus on already avid mobile game players. However, we understand that ethical aspects need to be taken into account in the future studies as aiming for optimal player experience, retention and advertisement can also have problematic causalities.

Some game-breaking bugs were revealed with the help of the Discord player base. Three players reported obvious bugs that were possibly related to using older Android devices. For instance, one player was able to press buttons in the main menu multiple times before the game would react in such a way that the buttons could no longer be pressed. One player suffered from a problem where the game would only display four large white rectangles on the black background. Additionally, some players reported that the game's frame rate would drop over time if the infinite map was generated over long enough time periods without the character dying. The infinite map generation also suffered from an instance where the background texture disappeared during gameplay. Problems which relate 
the uncontrolled test setup where participants use their own devices can be in the future excluded by organizing controlled experiments. However, this was not possible during the Spring 2021 due to the COVID-19 pandemic.

\section{CONCLUSION}

Situating advertisements in mobile games requires careful balancing between profit and optimal player experience. For an independent developer advertisement is however an important source of income in the market dominated by free to play mobile games. In this paper we report a process of designing and implementing a mobile game to study advertisement intrusiveness and how this influences aspects of player experience. In our survey with 51 participants divided into four groups based on what types of advertisements they were subjected to. We noticed that the number of advertisements seen did not seem to correlate strictly with the perceived intrusiveness.

\section{ACKNOWLEDGMENT}

This work has been partially funded by the European Commission grant PRINCE (815362) and the Business Finland funded project Reboot Finland IoT Factory 33/31/2018, supported by Academy of Finland 6Genesis Flagship (318927). We would like to thank all test players for their effort and valuable feedback.

\section{REFERENCES}

11] S. Kim, J. Lee, Y. Hwang, and S.-H. Jeong, "Effects of prominent ingame advertising in mobile media: Cognitive, affective, and behavioural outcomes and the moderating role of persuasion knowledge," International Journal of Mobile Communications, vol. 14, p. 203, 012016

[2] Z. Burns, I. Roseboom, and N. Ross, "The sensitivity of retention to in-game advertisements: An exploratory analysis," AAAI Conference on Artificial Intelligence and Interactive Digital Entertainment, 2016. [Online]. Available: https://aaai.org/ocs/index.php/AIIDE/AIIDE16/paper/view/14064

[3] J. Raveh, "In-game advertising in free-to-play mobile: Getting the balance right," https://www. gamasutra.com/blogs/JonathanRaveh/20160317/268363/ InGameAdvertisinginFreeToPlayMobileGettingtheBalanceRight.php, 2016, [Online; accessed 10-April-2021]

[4] A. L. Bang, P. Krogh, M. Ludvigsen, and T. Markussen, The role of hypothesis in constructive design research. Aalto University, 2012.

[5] M. Hirsimäki, "Between beats: linking player experience to advertisement frequency and intrusiveness," 2021. [Online]. Available: http://urn.fi/URN:NBN:fi:oulu-202105218114

[6] C. Khai, Y. Sha, and C. Richard, "Understanding the effect of incentivized advertising on the conversion funnel," http://dx.doi.org/10.2139/ ssrn. 3714353, 2021.

[7] MoPub, "Rewarded video ads drive performance for social casino advertiser," https://www.aarki.com/blog/ rewarded-video-ads-drive-performance-for-social-casino-advertiser, 2017, [Online; accessed 11-April-2021].

[8] AdColony, "Rewarded video \& prettygreat," https: //www.adcolony.com/wp-content/uploads/2017/02/ AdColony-Case-Study-Rewarded-Video-PrettyGreat.pdf, [Online; accessed 11-April-2021].

[11] B. Nerlich, Polysemy: flexible patterns of meaning in mind and language. Mouton de Gruyter, 2003.
[9] R. Smith, B. Kelly, H. Yeatman, C. Moore, L. Baur, L. King, E. Boyland, K. Chapman, C. Hughes, and A. Bauman, "Advertising placement in digital game design influences children's choices of advertised snacks: A randomized trial," Journal of the Academy of Nutrition and Dietetics, vol. 120, no. 3, pp. 404-413, 2020.

[10] Gilles Fauconnier and Mark Turner, "Conceptual integration networks," Cognitive Science, vol. 22, no. 2, pp. 133-187, 1998.

[12] L. Zbikowski, Conceptualizing music: cognitive structure, theory, and analysis. Oxford University Press, 2002.

[13] D. Reichelt, "Color switch," https://play.google.com/store/apps/details? id=com.colorswitch.switch2, 2015, [Online; accessed 21-February-2021. Developer: Reichelt, David. Publisher: Color Switch Phoenix LLC].

[14] B. Wissman, "Color switch: The mobile game as a multimedia powerhouse," https://www.forbes.com/sites/barrettwissman/2018/08/ 07/color-switch-the-mobile-game-as-a-multimedia-powerhouse/, 2018, [Online; accessed 21-February-2021].

[15] D. Takahashi, "After 40 mobile games, david reichelt hit gold with color switch," https://venturebeat.com/2018/03/31/ after-40-mobile-games-david-reichelt-hit-gold-with-color-switch/, 2018, [Online; accessed 21-February-2021].

[16] M. Michalko, Thinkertoys - A Handbook of Creative-Thinking Techniques, 2nd ed. Ten Speed Press, 2010.

[17] Gibbs, W. Raymond Jr., "Making good psychology out of blending theory," Cognitive Linguistics Journal, vol. 11-3/4, pp. 348-357, 2000.

[18] Brace Yourself Games, "Crypt of the necrodancer," https: //store.steampowered.com/app/247080/Crypt_of_the_NecroDancer/, 2015, [Online; accessed 15-February-2021]. Developer: Brace Yourself Games. Publisher: Brace Yourself Games and Klei Entertainment).

[19] J. Linietsky and A. Manzur, "Godot engine," https://godotengine.org/, 2020, [Version: v3.2.2.stable.official].

[20] The Audacity Team, "Audacity," https://www.audacityteam.org/, 2018, [Version: 2.3.3].

[21] DrMoriarty, "godot-applovin-max plugin," https://github.com/ DrMoriarty/godot-applovin-max, 2020, [Online; accessed 16-April2021].

[22] AppLovin, “Applovin max," https://www.applovin.com/max/, 2020, [Online; accessed 16-April-2021].

[23] M. Hirsimäki, "Work in progress game preview," https://youtu.be/ iXEZifi_uUQ, 2021, [Online; accessed 7-February-2021].

[24] A. Z. Abbasi, M. Umair Shah, U. Rehman, H. Hlavacs, D. Hooi Ting, and S. Nisar, "The role of personality factors influencing consumer video game engagement in young adults: A study on generic games," IEEE Access, vol. 9, pp. 17392-17410, 2021. [Online]. Available: https://doi.org/10.1109/ACCESS.2021.3053207

[25] A. Z. Abbasi, H. Hlavacs, and D. Hooi Ting, "Engagement in games: Developing an instrument to measure consumer videogame engagement and its validation," Int. J. Comput. Games Technol., vol. 2017, pp. 7363925:1-7363925:10, 2017. [Online]. Available: https://dx.doi.org/10.1155/2017/7363925

[26] H. Zaheer and D. G. Mark, "The attitudes, feelings, and experiences of online gamers: A qualitative analysis," CyberPsychology \& Behavior, vol. 12 , no. 6 , p. 747-753, 2009.

[27] A. Z. Abbasi, D. H. Ting, and H. Hlavacs, "Engagement in games: developing an instrument to measure consumer videogame engagement and its validation," International Journal of Computer Games Technology, vol. 2017, 2017.

[28] A. Z. Abbasi, M. U. Shah, U. Rehman, H. Hlavacs, D. H. Ting, and S. Nisar, "The role of personality factors influencing consumer video game engagement in young adults: A study on generic games," IEEE Access, vol. 9, pp. 17392-17410, 2021. 